\title{
Localization of white-matter lesions and effect of vascular risk factors in late-onset major depression
}

\author{
R. B. Dalby ${ }^{1 *}$, M. M. Chakravarty ${ }^{2,3,4}$, J. Ahdidan ${ }^{1}$, L. Sørensen ${ }^{5}$, J. Frandsen ${ }^{4}$, K. Y. Jonsdottir ${ }^{4}$, \\ E. Tehrani ${ }^{1}$, R. Rosenberg ${ }^{1}$, L. Østergaard ${ }^{4}$ and P. Videbech $^{1}$ \\ ${ }^{1}$ Center for Psychiatric Research, Aarhus University Hospital, Risskov, Denmark \\ ${ }^{2}$ Allen Institute for Brain Science, Seattle, WA, USA \\ ${ }^{3}$ PET Center, Aarhus University Hospital, Aarhus Sygehus, Aarhus, Denmark \\ ${ }^{4}$ Center of Functionally Integrative Neuroscience (CFIN), Aarhus University, Aarhus, Denmark \\ ${ }^{5}$ Department of Neuroradiology, Aarhus University Hospital, Aarhus Sygehus, Aarhus, Denmark
}

Background. Several studies suggest that patients with late-onset major depression (MD) have an increased load of cerebral white-matter lesions (WMLs) compared with age-matched controls. Vascular risk factors such as hypertension and smoking may confound such findings. Our aim was to investigate the association between the localization and load of WMLs in late-onset MD with respect to vascular risk factors.

Method. We examined 22 consecutive patients with late-onset first-episode MD and 22 age- and gender-matched controls using whole-brain magnetic resonance imaging (MRI). The localization, number and volume of WMLs were compared between patients and controls, while testing the effect of vascular risk factors.

Results. Among subjects with one or more WMLs, patients displayed a significantly higher WML density in two white-matter tracts: the left superior longitudinal fasciculus and the right frontal projections of the corpus callosum. These tracts are part of circuitries essential for cognitive and emotional functions. Analyses revealed no significant difference in the total number and volume of WMLs between groups. Patients and controls showed no difference in vascular risk factors, except for smoking. Lesion load was highly correlated with smoking.

Conclusions. Our results indicate that lesion localization rather than lesion load differs between patients with late-onset MD and controls. Increased lesion density in regions associated with cognitive and emotional functions may be crucial in late-onset $\mathrm{MD}$, and vascular risk factors such as smoking may play an important role in the pathophysiology of late-onset MD, consistent with the vascular depression hypothesis.

Received 16 March 2009; Revised 10 August 2009; Accepted 28 September 2009; First published online 9 November 2009

Key words: Late-onset major depression, magnetic resonance imaging, white-matter hyperintensities, white-matter lesions, smoking, vascular risk factors.

\section{Introduction}

Several studies have demonstrated an increased frequency of cerebral white-matter lesions (WMLs) in patients with major depression (MD) compared with age-matched controls (Videbech, 1997), especially in late-onset and late-life MD (Herrmann et al. 2008). WMLs are identified as signal hyperintensities on proton-density or T2-weighted magnetic resonance imaging (MRI) and are traditionally classified based on their location and size (Fazekas et al. 2002). The lesions are thought to reflect underlying cerebrovascular disease (Pantoni \& Garcia, 1997; Thomas et al. 2002) and positive correlations between WMLs, age

* Address for correspondence: Dr R. B. Dalby, Center for Psychiatric Research, Aarhus University Hospital, Skovagervej 2, DK-8240 Risskov, Denmark.

(Email: rbdalby@dadlnet.dk) and vascular risk factors such as hypertension, diabetes and smoking have been demonstrated (Awad et al. 1986; Fazekas et al. 1993; Breteler et al. 1994; Liao et al. 1997). Women tend to have a higher WML load than men, and risk factors for WML development are seemingly gender specific (Sachdev et al. 2008), which is noteworthy regarding the higher prevalence of MD in women compared with men.

Although WMLs are implicated in a range of clinical conditions and also a frequent finding in healthy individuals past middle-age, their exact role in depression remains elusive because of differences in the reporting of lesion load and their relationship with confounding factors, such as age and vascular risk factors (Sachdev et al. 2008). In general, WMLs are associated with impaired cognitive functioning, for example in tasks of processing speed, memory and executive functions (Gunning-Dixon \& Raz, 2000). In addition to cognitive impairment (Goodwin, 1997; 
Austin et al. 2001; Herrmann et al. 2007), subcortical WMLs in elderly depressed patients have been associated with a poor treatment outcome (Hickie et al. 1995; Steffens et al. 2001; Taylor et al. 2003 b; Chen et al. 2006; Iosifescu et al. 2006) and a greater risk of subsequent dementia (Steffens et al. 2007).

The association between depression, WMLs and vascular risk factors is at the center of the vascular depression hypothesis (Krishnan \& McDonald, 1995; Alexopoulos et al. $1997 a$; Krishnan et al. 1997) and in the later refined concept of subcortical ischemic depression (Krishnan et al. 2004). The vascular depression hypothesis states that WMLs contribute to the development of depression by disrupting the prefrontal systems or their modulating pathways, either by single, localized lesions or by an accumulation of lesions exceeding a certain threshold (Alexopoulos et al. 1997a), thus defining a subset of late-life depression closely related to vascular disease. However, the association between vascular risk factors and geriatric depression has been inconsistent (Kales et al. 2005), depending on study design. In particular, the choice of healthy control subjects is crucial, balancing the patient population distribution of vascular risk factors, as emphasized in a recent study by Sheline et al. (2008).

Over the past decade, research on WMLs and depression has shifted from focusing mainly on lesion load (i.e. lesion count, classification and volume) towards lesion localization. Recent research indicates that the exact localization of WMLs may be crucial in late-life MD (Sheline et al. 2008), and several studies of late-life MD have mainly found WMLs in subcortical regions and their frontal white-matter projections (Greenwald et al. 1998; MacFall et al. 2001; Taylor et al. 2003a; Videbech et al. 2004; O'Brien et al. 2006; Sheline et al. 2008), and in the basal ganglia (Videbech, 1997).

The aim of the present study was to investigate the association between the localization, number and volume of WMLs in a clinically well-described patient group with late-onset MD compared with a control group matched for age, gender and vascular risk factors. We tested the following hypotheses: (a) depressed patients have a greater lesion load (i.e. greater number and volume of WMLs) than controls, $(b)$ depressed patients have more WMLs located in the frontostriatal region than controls, and (c) vascular risk factors have a significant effect on lesion load.

\section{Method}

\section{Subjects}

Patients were consecutively recruited from the Neuropsychiatric Clinic, Aarhus University Hospital, Risskov, Denmark and from out-patient psychiatric clinics in the County of Aarhus, Denmark. We examined 22 patients with late-onset, first-episode MD and 22 controls matched for age and gender and with no previous history of psychiatric illness. All patients met DSM-IV criteria (APA, 2000) for MD and ICD-10 criteria (WHO, 1993) for moderate to severe depression within 4 weeks of examination. Late-onset was predefined as the debut of depressive symptoms after the age of 50 years. Controls were recruited through advertisement and sought matched for age and gender with the patient group. All subjects were assessed with selected parts of the SCAN structured interview (Wing et al. 1998) at the inclusion and were rated for severity of depressive symptoms and psychomotor retardation with the Bech-Rafaelsen Melancholia Scale (MES; Bech, 2002) and the Widlöcher Depressive Retardation Scale (WDRS; Widlöcher, 1983) respectively; all controls were additionally screened with the Mini-Mental State Examination (MMSE; Folstein et al. 1975). Both patients and controls were thoroughly interviewed about their medical history and were screened for concurrent medical diseases and alcohol abuse by standard blood tests, including thyroid function, and they all underwent a neurological examination. All subjects were right-handed, except for three patients and one control who were ambidextrous. Records of prescribed medication, including psychotropics, were obtained. At the time of inclusion nine patients were treated with selective serotonin reuptake inhibitors (SSRIs), six with tricyclic antidepressants (TCAs), eight with serotonin-norepinephrine reuptake inhibitors (SNRIs) and seven with noradrenergic and specific serotonin antidepressants (NaSSAs). Eight out of 22 patients received more than one antidepressant, and one patient was treatment naïve at inclusion. In addition, nine patients received anxiolytics and/or sedatives such as benzodiazepines, three received antipsychotics and one received an antiepilepticum for mood stabilization. None of the controls received any psychotropic medication.

Exclusion criteria for both groups were organic brain disease (e.g. former stroke, cerebral vascular malformations, epilepsy, or other known neurological diseases), former brain injury, substance dependency and conventional contraindications to undergo MRI scanning. After a complete description of the study to the subjects, written informed consent was obtained. The study was approved by the regional ethical committee.

\section{Vascular risk factors}

Information on vascular risk factors was carefully obtained during the clinical interview and a composite 
vascular risk score was calculated as defined in the Framingham Study (Wolf et al. 1991). Blood pressure (BP) was measured with an automated sphygmomanometer with a brachial cuff during rest and reported as a mean of three consecutive measures. Hypertension was defined as systolic BP $\geqslant 140 \mathrm{mmHg}$ and/or diastolic BP $\geqslant 90 \mathrm{mmHg}$ or the use of prescribed antihypertensive treatment. Diabetes was defined as fasting plasma glucose of minimum $7.0 \mathrm{~mm}$ and glycosylated hemoglobin (HbA1c) of minimum $6.2 \%$ or active antidiabetic treatment. Hypercholesterolemia was defined as lipid-lowering medication or fasting plasma values of total cholesterol $>6.5 \mathrm{~mm}$ or low density lipoprotein (LDL) $>4.0 \mathrm{~mm}$ or triglycerides $>4.0 \mathrm{~mm}$. Smoking status was divided into current, past (cessation at least 1 month prior to examination) or never. An estimate of lifetime tobacco consumption was measured in terms of so-called pack years ( 1 pack year being defined as a daily consumption of 20 cigarettes for 1 year). Tobacco other than cigarettes was converted to cigarette equivalents. Social class was determined according to education years and social position in Danish standards.

\section{MRI and image analysis}

MRI was performed on a whole-body 3-T Signa HDx GE scanner (GE Medical Systems, USA). The MRI protocol consisted of an axial fast spoiled gradient-echo (FSPGR) three-dimensional (3D) T1weighted sequence [inversion time $(\mathrm{TI})=750 \mathrm{~ms}$, flip angle $=14^{\circ}$, field of view $(\mathrm{FOV})=240 \mathrm{~mm}$, matrix $256 \times 256$, slice thickness $=1.2 \mathrm{~mm}$, no gap], an axial T2-weighted fluid-attenuated inversion recovery (FLAIR) sequence for visualizing WMLs [echo time $(\mathrm{TE}) 1=120 \mathrm{~ms}$, repetition time $(\mathrm{TR})=8650 \mathrm{~ms}, \mathrm{TI}=$ $2250 \mathrm{~ms}$, FOV $=240 \mathrm{~mm}$, matrix $224 \times 256$, slice thickness $=5 \mathrm{~mm}$, gap $=1.5 \mathrm{~mm}]$ and an axial T2weighted sequence $(\mathrm{TE}=112 \mathrm{~ms}, \mathrm{TR}=5400 \mathrm{~ms}$, $\mathrm{FOV}=240 \mathrm{~mm}$, matrix $416 \times 416$, slice thickness $=$ $5 \mathrm{~mm}$, gap $=1.5 \mathrm{~mm}$ ).

The T1-weighted images were non-linearly transformed to match the Montreal Neurological Institute (MNI) standard brain (Evans et al. 1994; Mazziotta et al. 2001). The subject-to-MNI space transformation was estimated using the ANIMAL algorithm (Collins et al. 1995; Robbins et al. 2004). The T2-weighted FLAIR images were rigidly matched to the T1weighted volumes and then non-linearly transformed to standard space using the concatenation of the linear and non-linear transformations (Collins et al. 1994, 1995).

A prefrontal region of interest (ROI), defined as the cortical areas anterior to the precentral sulcus with their underlying white matter and cerebral structures, was manually labeled in the MNI standard brain and matched back to the original FLAIR images using the inverse subject-to-MNI space transformation. These manual labels were later used for WML volume and number estimation.

\section{WMLs}

Subcortical and deep WMLs, excluding periventricular WMLs, were identified on the FLAIR images by an experienced neuroradiologist (L.S.) blinded to subject status and were manually labeled on the FLAIR images using Display software (McConnell Brain Imaging Centre, MNI, McGill University, Canada). The individual lesion masks were resampled to the MNI standard space using the T1 transformation and blurred with a 4-mm full-width at halfmaximum (FWHM) Gaussian kernel to model the lesion probability and the uncertainty of the manual labeling.

\section{Statistical analyses}

Differences between patients and controls in sociodemographic data and clinical variables were evaluated with the Wilcoxon two-sample rank sum test (Mann-Whitney test) for continuous variables and Fisher's exact test for categorical variables.

Lesion counts were analyzed with a negative binomial regression, as overdispersion invalidates the use of the usual Poisson regression. Lesion volume was modeled with a log-Gaussian regression model. The group variable was included first, as this was the factor of main interest, and sociodemographic and clinical variables such as age, smoking and hypertension were added when significant with a forward inclusion procedure. All analyses were carried out using Stata release 9.2 (Stata Statistical Software, StataCorp LP, USA) with two-sided tests and a $5 \%$ level of significance.

To analyze the localization of WMLs, a voxel-based analysis of the WML densities was performed using FMRISTAT (Worsley et al. 2002). We used the method of Cao (1999) to identify significant clusters, defined as a minimum number of 26-connected voxels at $t<$ -3.17 or $t>3.17(p<0.05)$. All effects were tested on a voxel-by-voxel basis using two-tailed unpaired $t$ tests, and $t$ maps were examined for significant changes, including summary analyses of $t$-statistic images, based on the 3D Gaussian random field theory (Worsley et al. 1996). The effect of age and gender was studied using a voxel-wise regression analysis. The resultant images were reviewed in Register (McConnell Brain Imaging Centre). 
Table 1. Sociodemographic and clinical characteristics of patients with late-onset major depression and non-depressed controls

\begin{tabular}{|c|c|c|c|c|}
\hline & \multirow{2}{*}{$\begin{array}{l}\text { Patients } \\
(n=22)\end{array}$} & \multirow{2}{*}{$\begin{array}{l}\text { Controls } \\
(n=22)\end{array}$} & \multicolumn{2}{|c|}{ Statistics } \\
\hline & & & $z$ & $p$ \\
\hline Age (years), mean (s.D.) & $57.4(4.6)$ & $59.2(7.3)$ & 0.5 & 0.64 \\
\hline Lifetime tobacco consumption (pack years), mean (s.D.) & $21.4(19.6)$ & $6.6(9.8)$ & -3.1 & $0.002^{\mathrm{a}}$ \\
\hline Vascular risk factor score ${ }^{\mathrm{b}}$, mean (s.D.) & $6.9(4.7)$ & $6.8(4.4)$ & 0.05 & 0.96 \\
\hline MES score, mean (S.D.) & $16.5(5.8)$ & $0.3(0.8)$ & -5.9 & $<0.001^{\mathrm{a}}$ \\
\hline WDRS score, mean (S.D.) & $16.0(8.3)$ & $0.5(0.6)$ & -5.8 & $<0.001^{\mathrm{a}}$ \\
\hline Gender, $n(\%)$ & & & & 1.00 \\
\hline Male & $7(31.8)$ & $7(31.8)$ & & - \\
\hline Female & $15(68.2)$ & $15(68.2)$ & & - \\
\hline Social class, $n(\%)$ & & & & $0.02^{\mathrm{a}}$ \\
\hline High & $12(54.6)$ & $20(90.9)$ & & - \\
\hline Low & $10(45.5)$ & $2(9.1)$ & & - \\
\hline Hypertension, $n(\%)$ & $11(50.0)$ & $12(54.6)$ & & 1.00 \\
\hline Smoking, $n(\%)$ & & & & $0.02^{\mathrm{a}}$ \\
\hline Current & $11(50.0)$ & $3(13.6)$ & & $0.02^{\mathrm{a}}$ \\
\hline Past & $8(36.4)$ & $9(40.9)$ & & 1.00 \\
\hline Never & $3(13.6)$ & $10(45.5)$ & & $0.05^{\mathrm{a}}$ \\
\hline Hypercholesterolemia, $n(\%)$ & $8(36.4)$ & $9(40.9)$ & & 1.00 \\
\hline Diabetes, $n(\%)$ & $1(4.6)$ & $1(4.6)$ & & 1.00 \\
\hline Cardiovascular disease, $n(\%)$ & $3(13.6)$ & $0(0.0)$ & & 0.23 \\
\hline
\end{tabular}

MES, Bech-Rafaelsen Melancholia Scale (Bech, 2002); WDRS, Widlöcher Depressive Retardation Scale (Widlöcher, 1983) ; S.D., standard deviation.

a Significant results at $p<0.05$.

${ }^{\mathrm{b}}$ Composite vascular risk factor score as described in the Framingham Study (Wolf et al. 1991), comprising age, systolic blood pressure, antihypertensive treatment, diabetes, cigarette smoking, cardiovascular disease (coronary heart disease, cardiac failure or intermittent claudication), atrial fibrillation and left ventricular hypertrophia.

The comparison of patients and controls, adjusted for age and gender, was initially performed for $(a)$ only subjects with WMLs, and then for (b) all subjects, including subjects without visible WMLs. All analyses were performed in the whole-brain volume and in the prefrontal ROI alone.

\section{Results}

\section{Sample characteristics}

The sociodemographic and clinical characteristics of all subjects are presented in Table 1. Patients and controls showed an equal distribution of age and gender. Social class was, however, significantly different between groups $(p=0.02)$, with more patients belonging to lower social classes. There was a statistically significant difference in overall smoking status $(p=0.02)$ and lifetime tobacco consumption ( $p=$ 0.002 ) between patients and controls, the patient group featuring more current smokers and more pack years, and the control group featuring more never smokers. There was no significant difference in the remaining vascular risk factors between the two groups.

\section{Lesion load}

Analyses showed no significant difference in either the number $(p=0.63)$ or volume $(p=0.65)$ of WMLs between patients and controls. In addition, there was no significant difference in the prefrontal fraction of WMLs between groups, either regarding the number $(p=0.18)$ or volume $(p=0.44)$ of lesions. With a forward inclusion procedure, we found a significant positive effect of smoking history (i.e. current or past smoking) on the total number of WMLs $(p=0.003)$ and a significant positive effect of pack years on the total volume of WMLs $(p=0.001)$; smokers generally had a higher lesion load than subjects reporting that they had never smoked. Subsequent adjustment for smoking status or pack years did not change the conclusion of no significant difference in the number or volume of lesions between groups. Analyses were repeated for the prefrontal region alone with similar results (data not shown).

Fig. 1 displays the volumes of individual lesions in patients and controls; regression analysis showed no difference in the mean individual lesion size between the two groups $(p=0.58)$. 
(a)

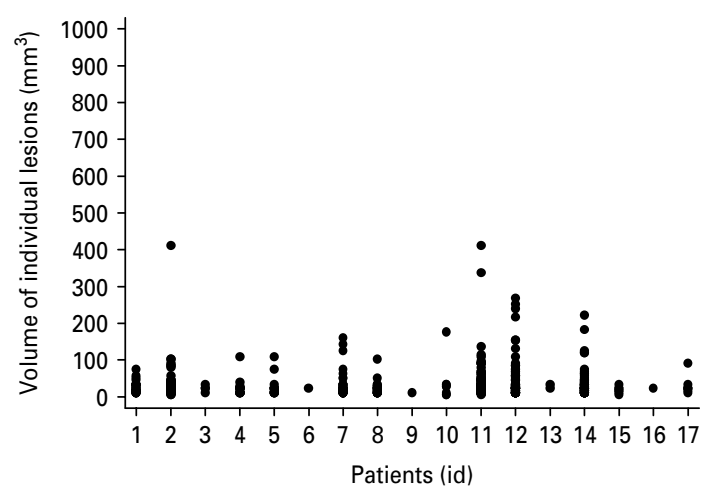

(b)

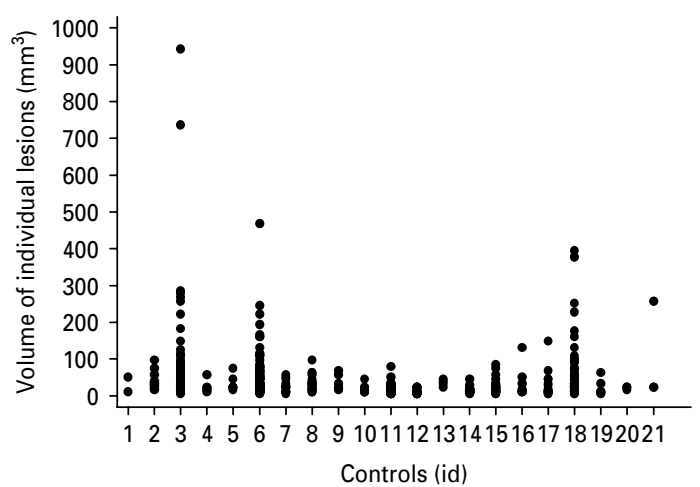

Fig. 1. Scatter plots of the volume of individual white-matter lesions (WMLs) in (a) depressed patients and (b) non-depressed controls. Only subjects with one or more WMLs are shown (17 patients and 21 controls, respectively). Statistical analysis showed no significant difference in individual lesion volume between groups.

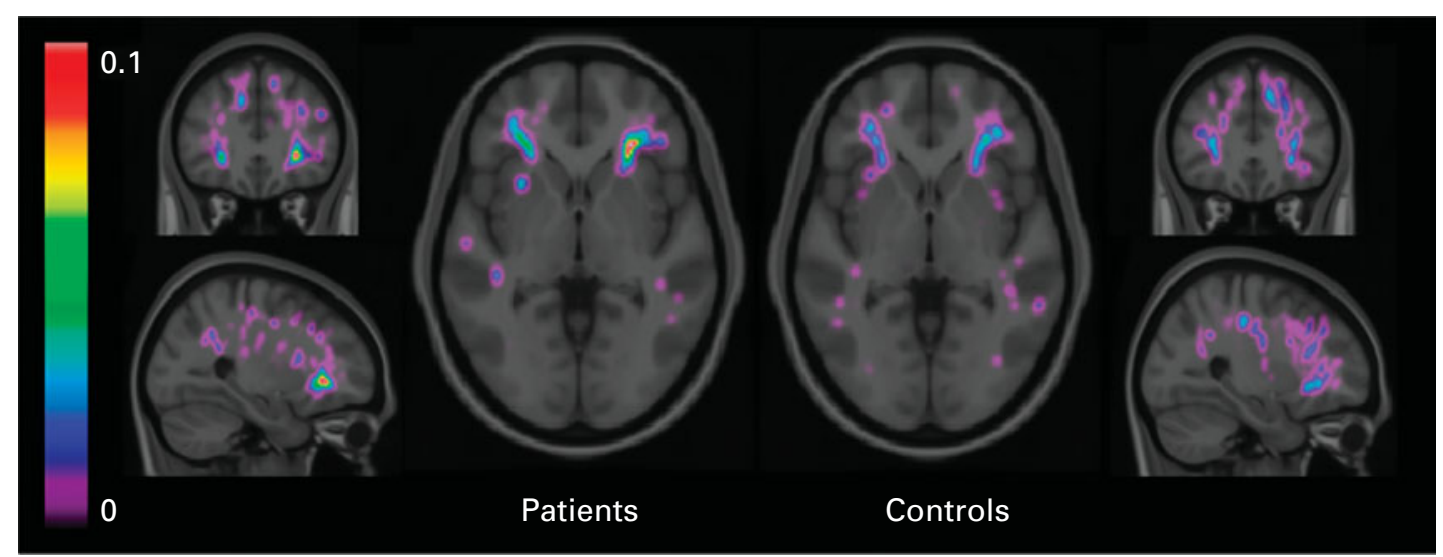

Fig. 2. Map in three planes (coronal, sagittal and axial views respectively) illustrating the average white-matter lesion (WML) density in patients (left) and controls (right) with one or more lesions (17 patients and 21 controls, respectively), adjusted for age and gender. The scale on the color bar is arbitrary as the average image is calculated from blurred lesion masks. In both groups, the highest lesion density is seen in the orbitofrontal white matter bilaterally.

\section{Localization of lesions}

Fig. 2 shows an average map of the lesion density in patients $(n=17)$ and controls $(n=21)$ with one or more WMLs, adjusted for age and gender, thus representing lesion localization. Subjects without lesions (five patients and one control) were excluded here, as our hypothesis on lesion localization was only relevant for subjects who presented with WMLs. The WMLs were widespread throughout the subcortical and deep white matter in both hemispheres, but most prominent in the orbitofrontal region bilaterally for both groups.

Voxel-based analyses on lesion density in subjects with one or more WMLs showed a significantly higher lesion density in the patients compared with the controls, adjusted for age and gender, in two regions: (1) the white-matter area just between the left precentral and postcentral gyrus $(p=0.031)$ and (2) the right superior frontal gyrus $(p=0.037)$, as illustrated in Fig. 3 . A third region in the right inferior frontal gyrus with a tendency towards significance was also found $(p=0.091)$. The subjects with WMLs in the two significant areas (clusters A and B in Fig. 3) were all current or past smokers. Clinical scores of depressive symptom severity (MES score) and psychomotor retardation (WDRS score) among the patients with one or more WMLs were not significantly correlated with the specific localization of WMLs in the two significant clusters, A (MES: $p=0.70$; WDRS: $p=0.66$ ) and B (MES: $p=0.28$; WDRS : $p=0.91$ ).

When including subjects without WMLs, voxelbased analyses showed no significant differences in the localization of WMLs between patients $(n=22)$ and controls $(n=22)$, adjusted for age and gender $(p=0.24)$. 


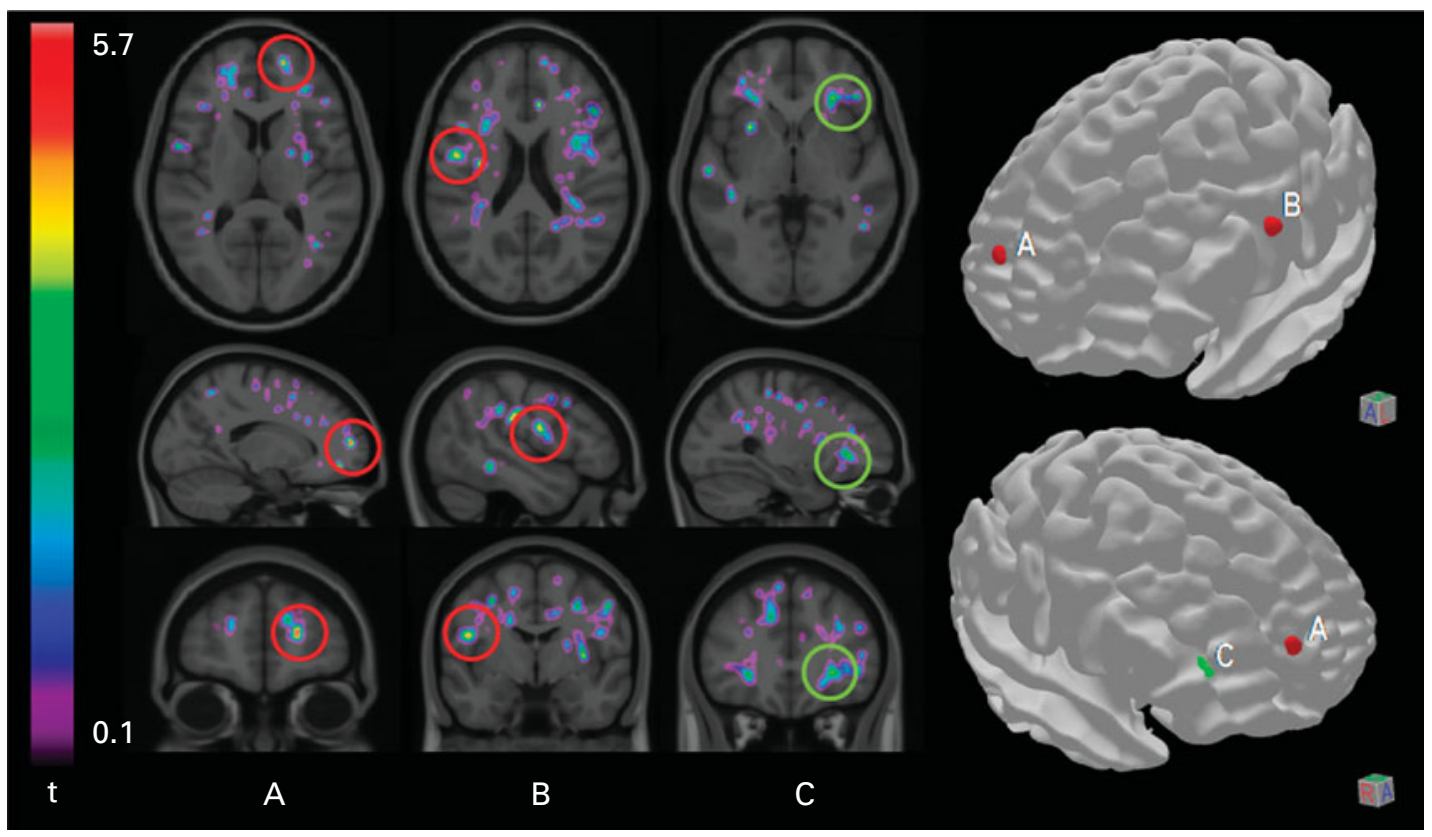

Fig. 3. Differences in lesion localization between depressed patients and non-depressed controls. The panel on the left shows selected slices of a $t$-statistic map representing the difference in mean white-matter lesion (WML) density in patients compared with controls among subjects with one or more lesions (17 patients and 21 controls, respectively), adjusted for age and gender. Setting the threshold at $t>3.17$ yields two clusters, A and B (red circles), with significantly higher WML density in patients compared with controls ( $p<0.05$, corrected). A third cluster, C (green circles), with a tendency towards significance $(p=0.091)$ is also shown. The clusters are illustrated in the right panel, where the semi-transparent display allows the clusters to be seen more three dimensionally in oblique left (anterior-left) and oblique right view (anterior-right). The images are created by overlaying a non-transparent rendering of clusters on a semi-transparent surface rendering of a standard brain. The significant red clusters are localized in the right superior frontal gyrus corresponding to the most frontal projections of the corpus callosum (A) and near the left precentral sulcus, on the rim to the left parietal operculum, corresponding to the course of the left superior longitudinal fasciculus (B). The yellow cluster (C) with a tendency towards significance is situated in the right inferior frontal gyrus corresponding to the course of the right inferior fronto-occipital fasciculus and the right uncinate fasciculus.

Testing the effect of age and gender on lesion density revealed a significant interaction between age and gender on lesion density $(p<0.05)$; that is, the pattern of age-related lesion localization differed between women and men in both groups.

\section{Discussion}

In this MRI study on cerebral WMLs, patients with late-onset, first-episode MD were carefully matched with a non-psychiatric control group in terms of age, gender and several vascular risk factors. We detected extensive white-matter changes across all subjects, but found no significant difference in the number and volume of lesions between the two groups, contradicting our initial hypothesis. Although our findings show a high density of frontal WMLs across all subjects, we found a significant difference in the localization of the WMLs between patients and controls. Given the equal lesion load, our findings therefore indicate that, in terms of depression and WMLs, lesion localization is more important than lesion count or volume, as predicted in the second hypothesis. Of note, five patients and one control had no visible WMLs, suggesting that WMLs are not a necessary condition for late-onset MD but may contribute to the pathogenesis in a subgroup of late-life MD, in accordance with the vascular depression hypothesis (Krishnan \& McDonald, 1995; Alexopoulos et al. 1997a ; Krishnan et al. 1997).

Among the subjects with one or more WMLs, the patients displayed a significantly higher lesion density than the controls in two areas, A $(p=0.037)$ and B $(p=0.031)$, as illustrated in Fig. 3. A third cluster, C, showed a tendency towards significance $(p=0.091)$. Cluster A is localized in the right superior frontal gyrus, corresponding to the most frontal projections of the corpus callosum. This is a boundary zone of white matter underlying the medial prefrontal cortex (MPC), the dorsolateral prefrontal cortex (DLPFC), the anterior cingulate cortex (ACC) and the orbitofrontal cortex (OFC). The adjacent frontopolar region approximates to Brodmann area (BA) 10 (Brodmann \& Gary, 2006). These prefrontal areas and their 
subcortical circuits are thought to play an important role in various aspects of cognition, for example in decision making (Krawczyk, 2002), in the regulation of emotional behavior (Phillips et al. 2008), and in the strategic processes involved in memory retrieval and executive functions such as planning, abstract thinking and initiating appropriate actions (Salloway et al. 2001). Cognitive deficits relating to all areas have been described in the depression literature (Videbech et al. 2002; Rogers et al. 2004; Drevets, 2007).

Cluster B is localized in the white-matter area between the left precentral and postcentral gyrus, corresponding to the course of the left superior longitudinal fasciculus, on the rim to the left parietal operculum. This region approximates to BA6, which comprises the premotor cortex and supplementary motor area (SMA), and is traditionally thought to be involved in the planning of complex, coordinated movements in interaction with the primary motor cortex (Chouinard \& Paus, 2006). However, more recent research indicates that cortical motor circuits also contribute to different aspects of voluntary action, that is as a form of decision making, through complex networks involving the prefrontal cortex, the motor and sensory cortices, in addition to the parietal cortex (Haggard, 2008). As lack of volition is a key feature of depression, it is tempting to hypothesize that impairment of motor circuits may play a role in MD. In addition, the involvement of motor circuits might explain the frequent symptom of psychomotor retardation seen in late-onset MD (Alexopoulos et al. 1997b); we could, however, not demonstrate any association between psychomotor retardation, measured by WDRS, and the presence of WMLs in cluster B.

Cluster $\mathrm{C}$ is situated in the right inferior frontal gyrus, corresponding to the course of the inferior frontooccipital fasciculus and the uncinate fasciculus, the latter linking the frontal lobe to the anterior portion of the temporal lobe. Although not significant in our analysis, the tendency towards significance warrants a comment. The area approximates to the lateral OFC (BA 47), which plays a major role in the human reward system (Rolls, 2000; Krawczyk, 2002), and dysfunction of this reward system has been hypothesized to prompt the anhedonic symptoms of depression (Naranjo et al. 2001). Overall, our findings indicate that WMLs in late-onset MD may affect specific cerebral areas involved in both complex cognitive tasks and voluntary action.

Our study differs from previous studies of WMLs in several aspects. First, periventricular lesions (PVLs) were omitted from the assessment, and thus our analyses only included subcortical and deep WMLs. We made this decision on the basis of existing literature indicating that neuropathological differences exist between deep WMLs and PVLs (Fazekas et al. 1993), and that deep WMLs rather than PVLs are most strongly associated with depressive symptoms, consistent with the vascular depression hypothesis (Krishnan et al. 2006). Deep WMLs have also been found to be more common in elderly subjects presenting with late-onset MD (O'Brien et al. 1996). Similarly, in neuropathological analyses of brains from people with MD, subcortical WMLs were all ischemic (Thomas et al. 2002) whereas PVLs had multiple causes (Thomas et al. 2003).

The fact that we found no difference in the number or volume of WMLs between patients and controls is consistent with findings by Videbech et al. (2004), but contrary to numerous previous studies reporting an increased burden of WMLs in depression (Videbech, 1997; Herrmann et al. 2008). This might be because our study was underpowered for this specific question or because our patients and controls were matched for several vascular risk factors, which is contrary to the design of many previous studies. Furthermore, the high prevalence of WMLs in our control group is supported by larger population studies such as the Rotterdam Scan Study and the Atherosclerosis Risk in Communities Study (ARIC), which report a high prevalence of WMLs in a general study population (Liao et al. 1997; de Leeuw et al. 2001). Unexpectedly, our analyses showed a significant interaction between age and gender on lesion density, which we accounted for, and the gender-dependent effect of age on lesion localization must therefore be considered in future studies of late-onset and late-life MD.

Despite a significant difference in smoking status between groups, with almost 3.7 times more current smokers in the patient group, the patients and controls in our study have very similar composite vascular risk scores as defined by the Framingham Study (Wolf et al. 1991). This illustrates the importance of evaluating each vascular risk factor independently, because an otherwise clinically well-established composite score introduces the risk of masking the effect of a single exposure variable such as smoking. Accordingly, in the present study, smoking and lifetime tobacco consumption, measured as pack years, had the most significant effect on the number and volume of WMLs respectively, consistent with our third hypothesis. The co-morbidity between smoking and depression is well known, but complex, and is influenced by sociodemographic differences, such as lower socio-economic status (Swan \& Lessov-Schlaggar, 2007). It has been suggested that the relationship between smoking and MD is mediated largely by genetic factors, predisposing to both smoking and MD (Kendler et al. 1993). Smoking is also considered a risk factor for WMLs, possibly on the basis of long-term damaging 
effects attributed to atherosclerosis and oxidative stress (Jane-Llopis \& Matytsina, 2006). Of interest, in a community study of 228 men and 208 women aged 60-64 years, Sachdev et al. (2007) found that WMLs were more common in women with current smoking as a significant determinant, whereas hypertension, heart disease and high homocysteine levels were significant determinants in men. Given the higher prevalence of MD in women, this raises an important question about the role of smoking in the pathophysiology of depression, and whether late onset of depressive symptoms may be related to smoking habits and cumulative tobacco load. Although speculative, a high prevalence of smoking in the patient group may also indicate a smoking-related vulnerability towards depressive symptoms through yet undefined mechanisms, perhaps by predisposing to localized damaging effects on the brain microstructure, presenting as WMLs in brain regions particularly vulnerable in MD. Unfortunately, the cross-sectional design of our study does not allow us to conclude further on the confounding effects of smoking in late-onset MD.

Our study has several strengths. First, the equally high lesion count in patients and controls adds power to the significant findings in lesion localization. Second, our patients are consecutive, diminishing selection bias. The gender distribution resembles that of depression in the general population, that is twothirds are women. We use a personal structured interview, in contrast to self-rating scales, to confirm diagnosis and other medical data according to international diagnostic criteria. In addition, we confine the inclusion criteria to first-episode and late-onset disease to ensure a more homogeneous patient group. All subjects are well characterized based on clinical examination, MRI scanning and laboratory test results. Finally, the distribution of vascular risk factors is very similar in the two groups, except for smoking status, which is very important in terms of possible confounding effects as emphasized above.

However, our study also contains some limitations. We used a manual MRI segmentation method for the WMLs, which is time-consuming and prone to interand intra-rater variability; by using a single rater, the former was eliminated in this study. Although several automated segmentation methods exist, many still have limited accuracy for different lesion types (i.e. subcortical, deep and periventricular lesions). As we chose to ignore the PVLs for reasons described above, we preferred the manually labeled lesions for analysis in this study. The T2-weighted FLAIR sequence used for segmentation of WMLs had a 1.5-mm gap between slices and a slice thickness of $5 \mathrm{~mm}$. These parameters, although consistent through the material, are not ideal and may cause sampling errors with respect to the definition of the WMLs. We defined late onset by a lower age limit of 50 years, which is younger than the majority of other studies, which have a lower age limit of 60-65 years. Significantly more patients than controls were classified as belonging to a lower social class, which supports epidemiological reports of an inverse correlation between socio-economic factors and mental illness, including depression (Hudson, 2005); however, this causality is complex, as lower socio-economic status can be both a predictor and a consequence of depression. Our patients, except for one, were not treatment naïve regarding psychotropic drugs, but this is not considered important for the development of WMLs (Videbech, 1997; Herrmann et al. 2008). Finally, the size of our sample may limit the statistical power of our findings, increasing the risk of type 2 statistical errors. We cannot preclude that the lack of significant between-group differences on lesion load may be due to an insufficient sample size.

In conclusion, we found that more patients with first-episode late-onset MD than non-depressed controls have WMLs localized in the frontostriatal area, despite an equal lesion load and similar vascular risk score. Our results suggest that the lesion localization is more important than the lesion load, and that the effect of age on lesion localization is gender dependent. We also show that vascular risk factors such as smoking have an effect on the number and volume of WMLs, and thus our study supports the vascular depression hypothesis in terms of an association between WMLs and depression, with smoking (past or present) as an important risk factor. A greater emphasis on vascular risk factors and their impact on cerebral microstructure may contribute to a more differentiated diagnostic approach to MD, with implications for future prevention and treatment.

\section{Acknowledgments}

We thank radiographers D. Zeidler and M. Geneser, CFIN, Aarhus University, Aarhus, Denmark for technical assistance on the MRI scans, L. Foldager, Centre for Psychiatric Research, Aarhus University Hospital, Risskov, Denmark for statistical support, and consultant, Ph.D., P. Mogensen, Regionshospitalet Hammel Neurocenter, Hammel, Denmark for carrying out the neurological examinations. Financial support was received from The Danish Medical Research Council, 'Forskningsfonden til Støtte af Psykiatrisk Forskning i Region Midtylland', The Eli Lilly Psychiatric Research Foundation, The A.P. Møller Foundation for the Advancement of Medical Science, 'Eli og Egon Larsens Fond', 'Slagtermester Max Wørzner og hustru Inger Wørzners Mindelegat', The AstraZeneca Travel Grant for Danish Psychiatrists, 'Helga og Peter 
Kornings Fond', 'Direktør Jacob Madsen og hustru Olga Madsens Fond', 'Overlæge, dr.med. Poul M. Færgemans Legat', 'Læge Frk. K. Rasmussens Mindelegat', 'Læge Eilif Trier-Hansen og hustru Ane Trier-Hansens Legat', 'Fonden til Forskning af Sindslidelser', 'Psykiatrisk Forskningsfond af 1967', 'Overlæge, dr.med. Einar Geert-Jørgensen og hustru Ellen Geert-Jørgensens Forskningslegat', and 'Dansk Psykiatrisk Selskabs Rejse- og Uddannelsesfond'.

\section{Declaration of Interest}

None.

\section{References}

Alexopoulos GS, Meyers BS, Young RC, Campbell S, Silbersweig D, Charlson M (1997a). 'Vascular depression' hypothesis. Archives of General Psychiatry 54, 915-922.

Alexopoulos GS, Meyers BS, Young RC, Kakuma T, Silbersweig D, Charlson M (1997b). Clinically defined vascular depression. American Journal of Psychiatry 154, 562-565.

APA (2000). Diagnostic and Statistical Manual of Mental Disorders, 4th edn, text revision. American Psychiatric Association: Washington, DC.

Austin MP, Mitchell P, Goodwin GM (2001). Cognitive deficits in depression: possible implications for functional neuropathology. British Journal of Psychiatry 178, 200-206.

Awad IA, Spetzler RF, Hodak JA, Awad CA, Carey R (1986). Incidental subcortical lesions identified on magnetic resonance imaging in the elderly. I. Correlation with age and cerebrovascular risk factors. Stroke 17, 1084-1089.

Bech P (2002). The Bech-Rafaelsen Melancholia Scale (MES) in clinical trials of therapies in depressive disorders: a 20-year review of its use as outcome measure. Acta Psychiatrica Scandinavica 106, 252-264.

Breteler MMB, van Swieten JC, Bots ML, Grobbee DE, Claus JJ, van den Hout JHW, van Harskamp F, Tanghe HLJ, de Jong PTVM, van Gijn J, Hofman A (1994). Cerebral white matter lesions, vascular risk factors, and cognitive function in a population-based study: the Rotterdam Study. Neurology 44, 1246-1252.

Brodmann K, Gary LJ (2006). Brodmann's Localisation in the Cerebral Cortex: The Principles of Comparative Localisation in the Cerebral Cortex based on Cytoarchitectonics. Springer: New York, NY.

Cao J (1999). The size of the connected components of excursion sets of x2, T and F fields. Advances in Applied Probability 31, 579-595.

Chen PS, McQuoid DR, Payne ME, Steffens DC (2006). White matter and subcortical gray matter lesion volume changes and late-life depression outcome: a 4-year magnetic resonance imaging study. International Psychogeriatrics 18, 445-456.
Chouinard PA, Paus T (2006). The primary motor and premotor areas of the human cerebral cortex. Neuroscientist 12, 143-152.

Collins DL, Holmes CJ, Peters TM, Evans AC (1995).

Automatic 3-D model-based neuroanatomical segmentation. Human Brain Mapping 3, 190-208.

Collins DL, Neelin P, Peters TM, Evans AC (1994). Automatic 3D intersubject registration of MR volumetric data in standardized Talairach space. Journal of Computer Assisted Tomography 18, 192-205.

de Leeuw FE, de Groot JC, Achten E, Oudkerk M, Ramos LM, Heijboer R, Hofman A, Jolles J, van Gijn J, Breteler MM (2001). Prevalence of cerebral white matter lesions in elderly people: a population based magnetic resonance imaging study. The Rotterdam Scan Study. Journal of Neurology, Neurosurgery and Psychiatry 70, 9-14.

Drevets WC (2007). Orbitofrontal cortex function and structure in depression. Annals of the New York Academy of Sciences 1121, 499-527.

Evans AC, Collins DL, Mills SR, Brown ED, Kelly RL, Peters TM (1994). 3D statistical neuroanatomical models from 305 MRI volumes. In Proceedings of the 1993 IEEE Nuclear Science Symposium \& Medical Imaging Conference. San Francisco, CA, USA: IEEE, pp. 1813-1817.

Fazekas F, Barkhof F, Wahlund LO, Pantoni L, Erkinjuntti T, Scheltens P, Schmidt R (2002). CT and MRI rating of white matter lesions. Cerebrovascular Diseases 13 (Suppl. 2), 31-36.

Fazekas F, Kleinert R, Offenbacher H, Schmidt R, Kleinert G, Payer F, Radner H, Lechner H (1993). Pathologic correlates of incidental MRI white matter signal hyperintensities. Neurology 43, 1683-1689.

Folstein MF, Folstein SE, McHugh PR (1975). 'Mini-mental

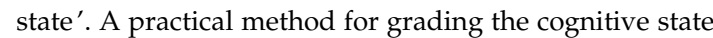
of patients for the clinician. Journal of Psychiatric Research 12, 189-198.

Goodwin GM (1997). Neuropsychological and neuroimaging evidence for the involvement of the frontal lobes in depression. Journal of Psychopharmacology 11, 115-122.

Greenwald BS, Kramer-Ginsberg E, Krishnan KR, Ashtari M, Auerbach C, Patel M (1998). Neuroanatomic localization of magnetic resonance imaging signal hyperintensities in geriatric depression. Stroke 29, 613-617.

Gunning-Dixon FM, Raz N (2000). The cognitive correlates of white matter abnormalities in normal aging: a quantitative review. Neuropsychology 14, 224-232.

Haggard P (2008). Human volition: towards a neuroscience of will. Nature Reviews Neuroscience 9, 934-946.

Herrmann LL, Goodwin GM, Ebmeier KP (2007). The cognitive neuropsychology of depression in the elderly. Psychological Medicine 37, 1693-1702.

Herrmann LL, Le Masurier M, Ebmeier KP (2008). White matter hyperintensities in late life depression: a systematic review. Journal of Neurology, Neurosurgery and Psychiatry 79, 619-624.

Hickie I, Scott E, Mitchell P, Wilhelm K, Austin MP, Bennett B (1995). Subcortical hyperintensities on magnetic resonance imaging: clinical correlates and prognostic 
significance in patients with severe depression. Biological Psychiatry 37, 151-160.

Hudson CG (2005). Socioeconomic status and mental illness: tests of the social causation and selection hypotheses. American Journal of Orthopsychiatry 75, 3-18.

Iosifescu DV, Renshaw PF, Lyoo IK, Lee HK, Perlis RH, Papakostas GI, Nierenberg AA, Fava M (2006). Brain white-matter hyperintensities and treatment outcome in major depressive disorder. British Journal of Psychiatry 188, 180-185.

Jane-Llopis E, Matytsina I (2006). Mental health and alcohol, drugs and tobacco: a review of the comorbidity between mental disorders and the use of alcohol, tobacco and illicit drugs. Drug and Alcohol Review 25, 515-536.

Kales HC, Maixner DF, Mellow AM (2005). Cerebrovascular disease and late-life depression. American Journal of Geriatric Psychiatry 13, 88-98.

Kendler KS, Neale MC, MacLean CJ, Heath AC, Eaves LJ, Kessler RC (1993). Smoking and major depression. A causal analysis. Archives of General Psychiatry 50, 36-43.

Krawczyk DC (2002). Contributions of the prefrontal cortex to the neural basis of human decision making. Neuroscience and Biobehavioral Reviews 26, 631-664.

Krishnan KR, Hays JC, Blazer DG (1997). MRI-defined vascular depression. American Journal of Psychiatry 154, 497-501.

Krishnan KR, McDonald WM (1995). Arteriosclerotic depression. Medical Hypotheses 44, 111-115.

Krishnan KR, Taylor WD, McQuoid DR, MacFall JR, Payne ME, Provenzale JM, Steffens DC (2004). Clinical characteristics of magnetic resonance imaging-defined subcortical ischemic depression. Biological Psychiatry 55, 390-397.

Krishnan MS, O'Brien JT, Firbank MJ, Pantoni L, Carlucci G, Erkinjuntti T, Wallin A, Wahlund LO, Scheltens P, van Straaten EC, Inzitari D (2006). Relationship between periventricular and deep white matter lesions and depressive symptoms in older people. The LADIS Study. International Journal of Geriatric Psychiatry 21, 983-989.

Liao D, Cooper L, Cai J, Toole J, Bryan N, Burke G, Shahar E, Nieto J, Mosley T, Heiss G (1997). The prevalence and severity of white matter lesions, their relationship with age, ethnicity, gender, and cardiovascular disease risk factors: the ARIC Study. Neuroepidemiology 16, 149-162.

MacFall JR, Payne ME, Provenzale JE, Krishnan KR (2001). Medial orbital frontal lesions in late-onset depression. Biological Psychiatry 49, 803-806.

Mazziotta J, Toga A, Evans A, Fox P, Lancaster J, Zilles K, Woods R, Paus T, Simpson G, Pike B, Holmes C, Collins L, Thompson P, MacDonald D, Iacoboni M, Schormann T, Amunts K, Palomero-Gallagher N, Geyer S, Parsons L, Narr K, Kabani N, Le Goualher G, Boomsma D, Cannon T, Kawashima R, Mazoyer B (2001). A probabilistic atlas and reference system for the human brain: International Consortium for Brain Mapping (ICBM). Philosophical Transactions of the Royal Society B : Biological Sciences 356, 1293-1322.
Naranjo CA, Tremblay LK, Busto UE (2001). The role of the brain reward system in depression. Progress in Neuro-Psychopharmacology and Biological Psychiatry 25, 781-823.

O'Brien J, Desmond P, Ames D, Schweitzer I, Harrigan S, Tress B (1996). A magnetic resonance imaging study of white matter lesions in depression and Alzheimer's disease. British Journal of Psychiatry 168, 477-485.

O'Brien JT, Firbank MJ, Krishnan MS, van Straaten EC, van der Flier WM, Petrovic K, Pantoni L, Simoni M, Erkinjuntti T, Wallin A, Wahlund LO, Inzitari D (2006). White matter hyperintensities rather than lacunar infarcts are associated with depressive symptoms in older people: the LADIS study. American Journal of Geriatric Psychiatry 14, 834-841.

Pantoni L, Garcia JH (1997). Pathogenesis of leukoaraiosis: a review. Stroke 28, 652-659.

Phillips ML, Ladouceur CD, Drevets WC (2008). A neural model of voluntary and automatic emotion regulation: implications for understanding the pathophysiology and neurodevelopment of bipolar disorder. Molecular Psychiatry 13, 829-857.

Robbins S, Evans AC, Collins DL, Whitesides S (2004). Tuning and comparing spatial normalization methods. Medical Image Analysis 8, 311-323.

Rogers MA, Kasai K, Koji M, Fukuda R, Iwanami A, Nakagome K, Fukuda M, Kato N (2004). Executive and prefrontal dysfunction in unipolar depression: a review of neuropsychological and imaging evidence. Neuroscience Research 50, 1-11.

Rolls ET (2000). The orbitofrontal cortex and reward. Cerebral Cortex 10, 284-294.

Sachdev P, Chen X, Wen W (2008). White matter hyperintensities in mid-adult life. Current Opinion in Psychiatry 21, 268-274.

Sachdev PS, Parslow R, Wen W, Anstey KJ, Easteal S (2007). Sex differences in the causes and consequences of white matter hyperintensities. Neurobiology of Aging 30, 946-956.

Salloway S, Malloy P, Duffy JD (2001). The Frontal Lobes and Neuropsychiatric Illness, 1st edn. American Psychiatric Publishing: Washington, DC.

Sheline YI, Price JL, Vaishnavi SN, Mintun MA, Barch DM, Epstein AA, Wilkins CH, Snyder AZ, Couture L, Schechtman K, McKinstry RC (2008). Regional white matter hyperintensity burden in automated segmentation distinguishes late-life depressed subjects from comparison subjects matched for vascular risk factors. American Journal of Psychiatry 165, 524-532.

Steffens DC, Conway CR, Dombeck CB, Wagner HR, Tupler LA, Weiner RD (2001). Severity of subcortical gray matter hyperintensity predicts ECT response in geriatric depression. Journal of ECT 17, 45-49.

Steffens DC, Potter GG, McQuoid DR, MacFall JR, Payne ME, Burke JR, Plassman BL, Welsh-Bohmer KA (2007). Longitudinal magnetic resonance imaging vascular changes, apolipoprotein E genotype, and development of dementia in the neurocognitive outcomes of depression in the elderly study. American Journal of Geriatric Psychiatry 15, 839-849. 
Swan GE, Lessov-Schlaggar CN (2007). The effects of tobacco smoke and nicotine on cognition and the brain. Neuropsychology Review 17, 259-273.

Taylor WD, MacFall JR, Steffens DC, Payne ME, Provenzale JM, Krishnan KR (2003a). Localization of age-associated white matter hyperintensities in late-life depression. Progress in Neuro-Psychopharmacology and Biological Psychiatry 27, 539-544.

Taylor WD, Steffens DC, MacFall JR, McQuoid DR, Payne ME, Provenzale JM, Krishnan KR (2003b). White matter hyperintensity progression and late-life depression outcomes. Archives of General Psychiatry 60, 1090-1096.

Thomas AJ, O'Brien JT, Barber R, McMeekin W, Perry R (2003). A neuropathological study of periventricular white matter hyperintensities in major depression. Journal of Affective Disorders 76, 49-54.

Thomas AJ, O'Brien JT, Davis S, Ballard C, Barber R, Kalaria RN, Perry RH (2002). Ischemic basis for deep white matter hyperintensities in major depression: a neuropathological study. Archives of General Psychiatry 59, 785-792.

Videbech P (1997). MRI findings in patients with affective disorder: a meta-analysis. Acta Psychiatrica Scandinavica 96, 157-168.

Videbech P, Ravnkilde B, Gammelgaard L, Egander A, Clemmensen K, Rasmussen NA, Gjedde A, Rosenberg R (2004). The Danish PET/depression project: performance on Stroop's test linked to white matter lesions in the brain. Psychiatry Research 130, 117-130.

Videbech P, Ravnkilde B, Pedersen TH, Hartvig H, Egander A, Clemmensen K, Rasmussen NA, Andersen F, Gjedde A, Rosenberg R (2002). The Danish PET/ depression project: clinical symptoms and cerebral blood flow. A regions-of-interest analysis. Acta Psychiatrica Scandinavica 106, 35-44.

WHO (1993). The ICD-10 Classification of Mental and Behavioural Disorders. Diagnostic Criteria for Research. World Health Organization: Geneva.

Widlöcher DJ (1983). Psychomotor retardation: clinical, theoretical, and psychometric aspects. Psychiatric Clinics of North America 6, 27-40.

Wing JK, Sartorius N, Üstün TB (1998). Diagnosis and Clinical Measurement in Psychiatry. A Reference Manual for $S C A N$. Cambridge University Press: Cambridge.

Wolf PA, D'Agostino RB, Belanger AJ, Kannel WB (1991). Probability of stroke: a risk profile from the Framingham Study. Stroke 22, 312-318.

Worsley KJ, Liao CH, Aston J, Petre V, Duncan GH, Morales F, Evans AC (2002). A general statistical analysis for fMRI data. NeuroImage 15, 1-15.

Worsley KJ, Marrett S, Neelin P, Vandal AC, Friston KJ, Evans AC (1996). A unified statistical approach for determining significant signals in images of cerebral activation. Human Brain Mapping 4, 58-73. 